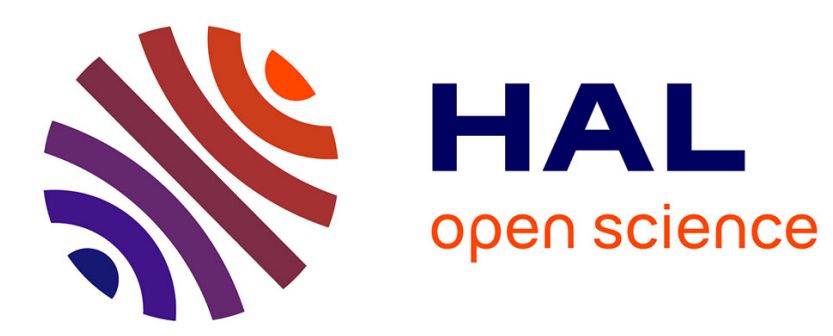

\title{
Strain hardening of aluminium alloy 3004 in the deep drawing and ironing processes
}

\author{
Joel Courbon, J. Duval
}

\section{To cite this version:}

Joel Courbon, J. Duval. Strain hardening of aluminium alloy 3004 in the deep drawing and ironing processes. Journal de Physique IV Proceedings, 1993, 03 (C7), pp.C7-247-C7-250. 10.1051/jp4:1993739 . jpa-00252157

\section{HAL Id: jpa-00252157 https://hal.science/jpa-00252157}

Submitted on 1 Jan 1993

HAL is a multi-disciplinary open access archive for the deposit and dissemination of scientific research documents, whether they are published or not. The documents may come from teaching and research institutions in France or abroad, or from public or private research centers.
L'archive ouverte pluridisciplinaire HAL, est destinée au dépôt et à la diffusion de documents scientifiques de niveau recherche, publiés ou non, émanant des établissements d'enseignement et de recherche français ou étrangers, des laboratoires publics ou privés. 


\title{
Strain hardening of aluminium alloy 3004 in the deep drawing and ironing processes
}

\author{
J. COURBON and J.L. DUVAL*
}

Pechiney CRV, BP. 27, 38340 Voreppe, France

* Laboratoire des Propriétés Mécaniques et Thermodynamiques des Matériaux (LPMTM-CNRS), Univ. Paris-Nord, avenue J.B. Clément, 93430 Villetaneuse, France

\begin{abstract}
The evolution of material hardening resulting from the canmaking operations on aluminium beverage cans has been investigated. Tensile tests in cup walls revealed that deep drawing induced softening in the hoop direction and hardening in the meridian direction. This anisotropy is retained in the ironing operation. Changes in strain path on a heavily cold-rolled material probably cause such a complex behaviour. To determine hardening laws for deep drawing, simple shear tests were thus performed because of the strain path similarity. They allowed to determine hardening laws over larger strains than tension could reach and revealed a saturation of stress. Altogether they proved adapted to the understanding of deep drawing.
\end{abstract}

\section{INTRODUCTION}

Aluminium alloy 3004 is commonly used for the production of beverage can bodies. It consists of commercial purity aluminium $(0,4 \mathrm{wt} \% \mathrm{Fe}$ and $0,2 \mathrm{wt} \% \mathrm{Si})$ alloyed with $\mathrm{Mn}: 1 \mathrm{wt} \%, \mathrm{Mg}: 1 \mathrm{wt} \%$ and $\mathrm{Cu}: 0,15 \mathrm{wt} \%$ to give strengthening by solid solution, by Mn-based dispersoids and mostly by dislocations. Strain-hardening is especially important in this alloy : the elastic limit is about $70 \mathrm{MPa}$ in the annealed state and $280 \mathrm{MPa}$ in the cold-rolled sheets delivered to canmakers.

Cups are deep-drawn and redrawn from these sheets, then their wall is ironed through three dies, increasing the height of the can body while reducing its thickness. The deep drawing and ironing operations with their specific strain paths modify the hardening of the material. Besides the impact on the can body final properties such as vertical crush resistance, such effects must be incorporated into numerical simulations of the process to make them realistic. Thus a specific study of the evolution of hardening at the various stages of the process has been developed.

\section{CHANGES IN THE WALL MATERIAL}

Deep drawing results in a strain path close to pure shear (fig.1), there is a hoop shrinking and a meridian elongation. The shear directions vary with respect to the orthotropic rolling axes all around the can. The texture anisotropy resulting from the rolling operations, though kept as low as possible, results in light earing and thickness heterogeneities all around the cup wall.

Ironing strains are close to those of rolling with a through-thickness shear of the wall (fig.1). 

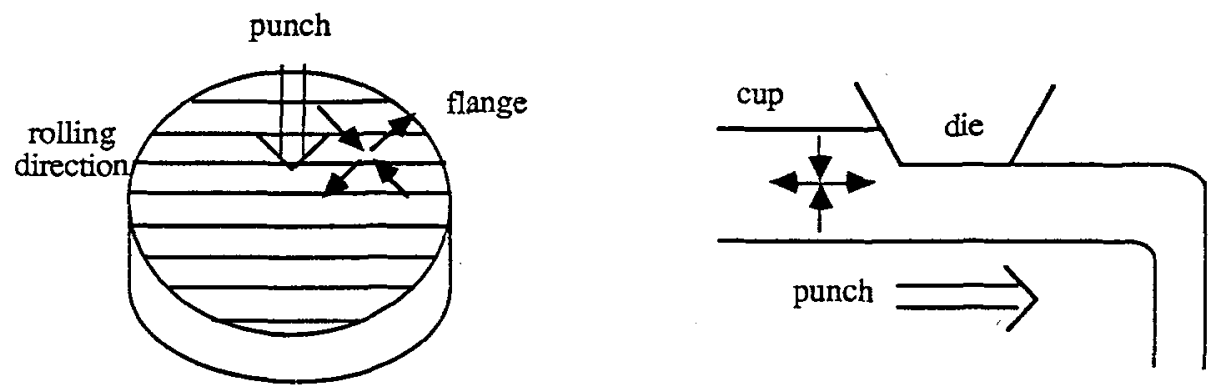

Fig.1 : sketch of the strains in the deep drawing and ironing operations.
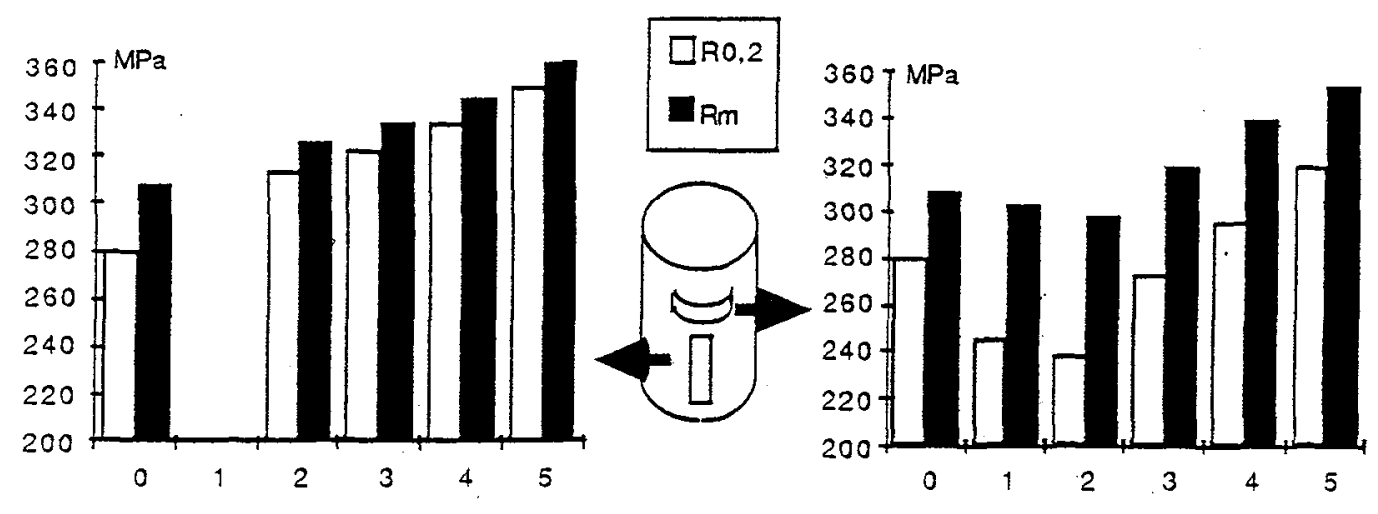

Fig. 2 : evolution of the $0,2 \%$ proof stress and tensile strength of cup walls, showing the difference between meridian (left) and hoop (right) specimens.

$O:$ as-rolled sheet $; 1:$ drow $; 2$ :redraw $; 3,4$ and 5 : ironing passes

The resulting changes in hardening have been evidenced by cutting hoop and meridian tensile specimens in cup walls. Care has been taken to measure the thickness at many points of the specimens, to account for heterogeneities. The averaged features are shown on Fig.2. The process parameters were : diameter at first draw $60 \%$, at second draw $48 \%$ of initial flange diameter ; wall thickness at first ironing pass $78 \%$, at second pass $58 \%$, at third pass $36 \%$ of initial sheet thickness. The meridian specimens tend to workharden all along the stages of the process. On the other hand, hoop specimens soften during drawing and redrawing.

Strain softening during deep drawing of aluminium alloys had previously been reported by Grimes $e t a l$. [1] and Merchant et al. [2]. Yet the situation is more complicated since only hoop specimens are actually softened. The change in strain path between rolling and deep drawing with subsequent dislocation annihilation probably accounts for the phenomenon. This is backed up by the recent findings of Shen [3] : a 3004 partially recovered after rolling has a more stable microstructure and does not soften during drawing. Afterwards, ironing work-hardens the material again. But the difference created between hoop and meridian specimens does not disappear.

Such tensile tests on cup walls already bring useful information on the material hardening; but they cannot explain the material behaviour in the deep drawing process : the only use of an arithmetic equivalent strain appears dubious since the hardening becomes negative. There is an effect of dislocation microstructure, and such an effect is linked with the change in strain path from rolling to deep drawing. To understand the softening, one has to develop a mechanical test close to this specific strain path, then develop macroscopic models including kinematic hardening, for isotropic hardening would never give rise to strain softening. Pure shear tests appear adapted to the situation : they are developped in the next section. 


\section{PURE SHEAR TESTS FOR DEEP DRAWING}

As stated, defining stress-strain laws adapted to the deep drawing operation is not straightforward. Strains of $50-60 \%$ are reached in cup walls. Tensile tests are not very useful since the strain path differs very much and the homogeneous ductility is limited to $5 \%$ because of the necking instability. Simple shear tests appear more adapted because of the strain similarity. Fig. 3 shows the principle of the test, essentially developed by Rauch et al. [4], that can be adapted to any tensile device. The instability to avoid is not necking but buckling, since one diagonal of the thin specimen is undergoing a compression. A proper choice of dimensions for the sheared zone is able to prevent it [5] : the specimens were $0,30 \mathrm{~mm}$ thick, $38 \mathrm{~mm}$ long and the sheared zone was $2 \mathrm{~mm}$ broad.

The specimens were taken at different angles to the rolling direction and a grid was printed parallel to the shear direction, to compare the strain monitored from the move of the machine to the one measured from grid deformation.

Fig.4 shows a typical stress-strain curve. Uniform strains are very much increased and the stress-strain laws differ from the ones observed in tension. Most noticeable is the absence of hardening after a certain amount of shear strain $(\approx 10 \%)$. This evolution could not be guessed from tensile testing, since the uniform tensile ductility of 3004 is too low (4\%): on the contrary, a Swift-type hardening $\sigma=K\left(\varepsilon+\varepsilon_{0}\right)^{\mathrm{n}}$ was observed up to tensile necking.

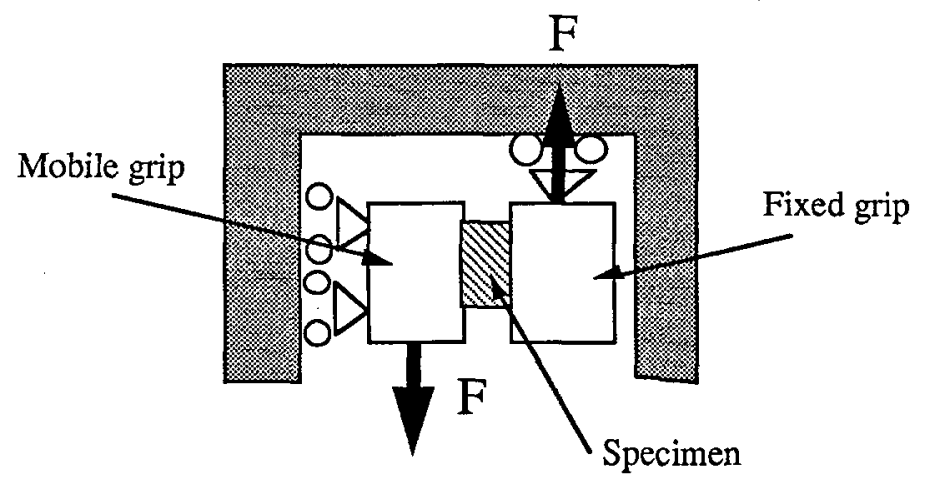

Fig.3 : shear testing device. The sheet is in the sketch plane, fastened in the fixed and mobile grips.

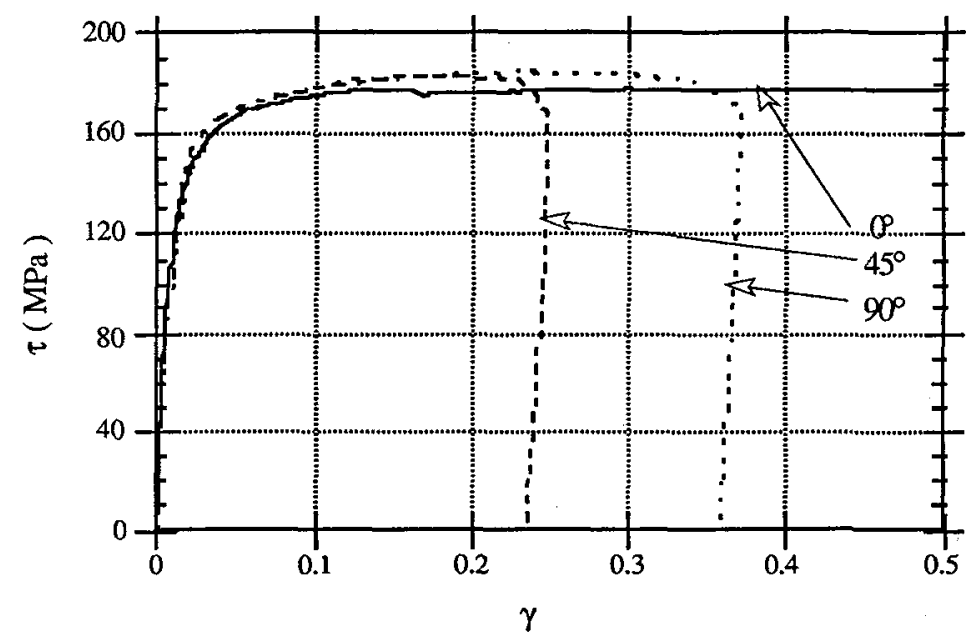

Fig.4 : shear stress $\tau$ / shear strain $\gamma$ curve (3004 sheared at $0,45,90^{\circ}$ to the rolling direction).

Strain localization provokes an early rupture at $45^{\circ}$ and $90^{\circ}$ when compared with shear at $0^{\circ}$ to the rolling direction. 
In order to translate the $\tau / \gamma$ (shear stress / plastic shear strain) curves into $\sigma / \varepsilon$ tensile curves, or vice-versa, a plasticity model is needed. Even though cold-rolled 3004 is not perfectly isotropic, we may use the von Mises yield criterion, which brings the equivalences : $\sigma=\sqrt{3} \tau$ and $\varepsilon=\gamma / \sqrt{3}$. A closer analysis of the curves in terms of the plastic power allowed to replace $\sqrt{3}$ by 1,9 .

Fig. 5 shows the comparison of tensile and shear curves in terms of $\tau / \gamma$. The Swift extrapolation of tensile curves clearly results in an overevaluation of the flow stress in the material, since no saturation of hardening was predictable in tension.

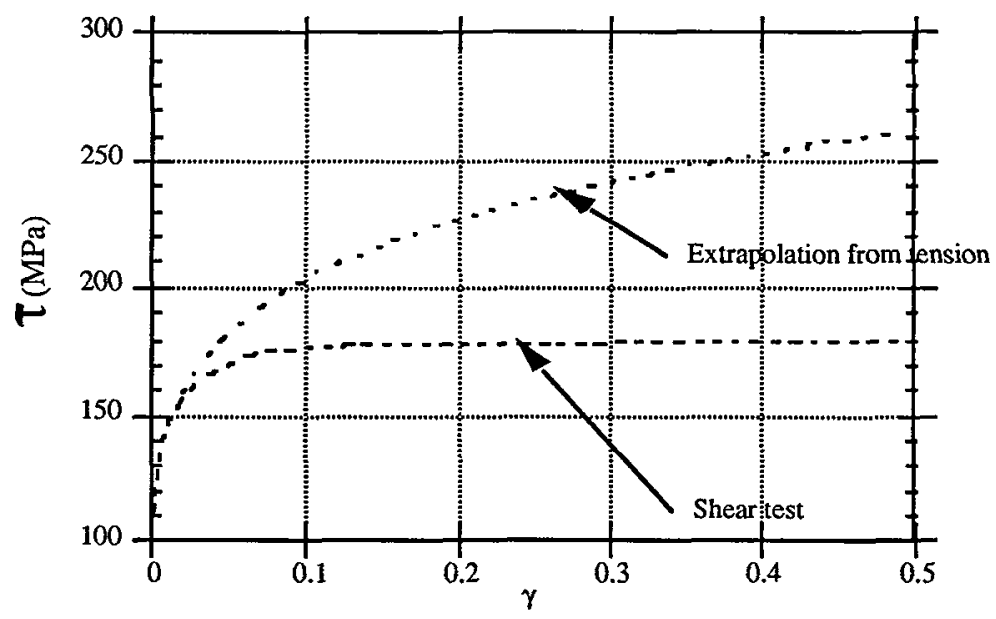

Fig.5 : comparison of equivalent shear stresses and strains brought from tensile tests and from pure shear tests. Tensile hardening has been extrapolated in the large strain range from the Swift law.

\section{IRONING}

A direct evaluation of the curve using force measurements in an ironing operation was not tried, since friction on both punch and die sides play a major role in the resulting forces when compared to workhardening. Tensile tests on can walls with different ironing reductions allow to define a stress-strain curve. After redrawing, there is a steep hardening but it then tends to saturation at ironing strains above 1.

\section{CONCLUSION}

Simple tensile tests performed on cup walls between stages of the canmaking operation allowed to detect hardening or softening effects linked with the strain path used. The mere use of isotropic hardening is not adapted to these forming operations, especially deep drawing. Ironing is more simple but comes on a structure modified by the deep drawing stages.

Simple shear tests proved useful to give an experimental stress-strain law because of their similarity to deep drawing and the large range of homogeneous deformation. A saturation of hardening was evidenced and the danger of extrapolating tensile curves to large deformations shown. Altogether, the simple shear test proved useful for sheet material characterization for deep drawing purposes.

\section{REFERENCES}

[1] Grimes R. and Wright J.C., J. Inst. Metals 95, (1968), 182.

[2] Merchant H.D., Hodgson D.S., O'Reilly I. and Embury J.D., Mats Character. 25 (1990), 251.

[3] Shen T.H., TMS Fall Meeting, Symp. on Aluminum Alloys for Packaging, Chicago, (1992).

[4] Rauch E.F. and G'Sell C., Mater. Sci. Eng. A111, (1989), 71.

[5] Genevois P., PhD Thesis, INP Grenoble, France (1992). 